\title{
$\beta-2$ microglobulin is unsuitable as an internal reference gene for the analysis of gene expression in human colorectal cancer
}

\author{
YASUHIRO NIHON-YANAGI ${ }^{1}$, KENSUKE TERAI ${ }^{2}$, TAKEYOSHI MURANO ${ }^{2}$, \\ TAKAYUKI KAWAI $^{2}$, SHINYA KIMURA ${ }^{1}$ and SHINICHI OKAZUMI ${ }^{3}$ \\ ${ }^{1}$ Division of Hematology, Respiratory Medicine and Oncology, Department of Internal Medicine, \\ Faculty of Medicine, Saga University, Saga 849-8501; Departments of ${ }^{2}$ Research and Development \\ and ${ }^{3}$ Surgery, Sakura Medical Center, Toho University, Chiba 285-0841, Japan
}

Received October 4, 2012; Accepted December 24, 2012

DOI: $10.3892 /$ br.2013.53

\begin{abstract}
It is well-known that gene expression levels should be normalized to a carefully selected and appropriately stable internal control gene. However, numerous studies have demonstrated that the expression of housekeeping (HK) genes, typically used as internal control genes varies considerably. A number of studies have shown that $\beta-2$ microglobulin (B2M), an $\mathrm{HK}$ gene, frequently used as an internal reference gene, is expressed at low levels in colorectal cancer tissue, when assessed using real-time reverse transcriptase-polymerase chain reaction (RT-PCR). Due to the fact that the expression levels of various HK genes vary depending on the tissue type or experimental conditions, it has been suggested that several control genes should be analyzed in parallel for certain tissues. In the present study, mRNA expression levels of toll-like receptors 2 (TLR2) and 4 (TLR4) in sporadic human colorectal cancerous and non-cancerous tissues were analyzed relative to three HK genes, $\beta$-glucuronidase (GUS), $\beta$-actin (BA) and $\mathrm{B} 2 \mathrm{M}$, using a commercially available tool. Relative expression levels were quantified using the three genes individually and together, and TLR 2 as well as TLR4 expression was compared in cancerous and non-cancerous colorectal tissue specimens. Consistent data were obtained in most cases when GUS and BA were used as internal control genes. When B2M was used as the internal control gene, TLR2 and TLR4 expression was demonstrated to be higher in cancerous compared to noncancerous colorectal tissues. These results were consistent with previous observations of low-level B2M expression in
\end{abstract}

Correspondence to: Dr Yasuhiro Nihon-Yanagi, Division of Hematology, Respiratory Medicine and Oncology, Department of Internal Medicine, Faculty of Medicine, Saga University, 5-1-1 Nabeshima, Saga 849-8501, Japan

E-mail: nihonyan@cc.saga-u.ac.jp

Key words: housekeeping gene, $\beta$-2 microglobulin, internal control, real-time polymerase chain reaction cancerous colorectal tissue and suggest that B2M may be inappropriate as an internal control gene for gene expression studies of colorectal cancer.

\section{Introduction}

Internal control genes are necessary for the accurate determination of gene expression using techniques such as quantitative real-time polymerase chain reaction (PCR). High-throughput real-time reverse transcriptase (RT)-PCR, with its outstanding sensitivity and accuracy, has rendered the selection of a housekeeping (HK) gene used as the internal standard for the estimation and comparison of mRNA levels even more important (1-3). Previous studies showed that the expression levels of commonly used HK genes are different in various tissues or between normal and diseased tissues (1,4-9).

It has been argued that since the expression levels of various HK genes differ depending on the tissue type or experimental conditions, more than one or even several various control genes should be assessed in parallel for certain tissues (1,3,10-12). In colorectal cancer (CRC), downregulation of the HK gene $\beta$-2 microglobulin (B2M) has been confirmed using real-time RT-PCR $(13,14)$.

In a previous study, we examined the expression of toll-like receptors 2 (TLR2) and 4 (TLR4) in sporadic human CRC tissue (15). TLRs are known to be involved in innate immunity and to play an important role in immune surveillance (16-20). In this study, we used a commercially available kit for analysis of the preferred internal control genes and selected three reference genes: $\beta$-glucuronidase (GUS), $\beta$-actin (BA) and B2M. Using these three internal control genes, the mRNA expression levels of TLR 2 and TLR4 in cancerous and non-cancerous colorectal tissue specimens were quantified using TaqMan real-time PCR and compared. Based on the results, we discuss the validity of each of the internal control genes in terms of accurate analysis of gene expression in CRC tissue under the present experimental conditions.

\section{Materials and methods}

Tissue specimens and internal control genes. Surgical specimens of colorectal tissue were obtained from $50 \mathrm{CRC}$ patients 


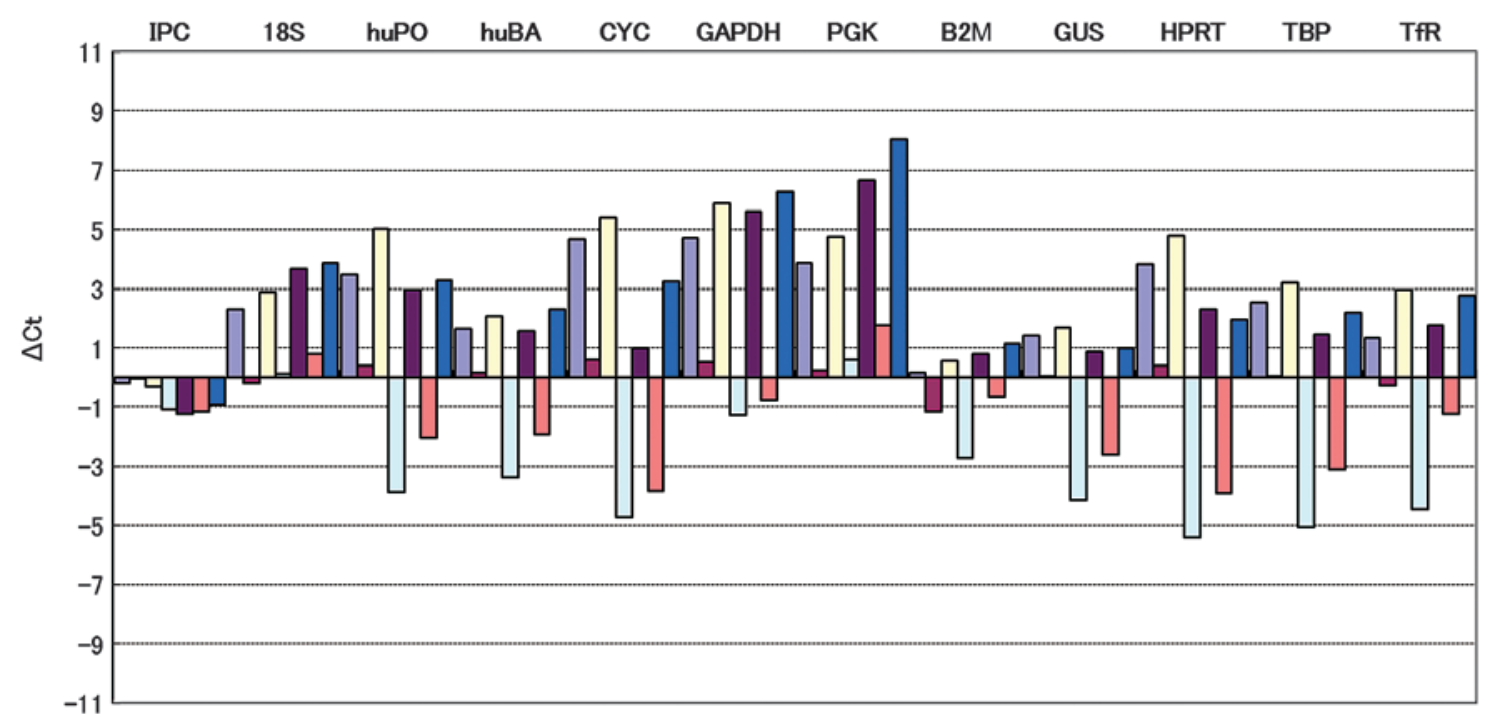

Figure 1. Columns represent individual samples analyzed using TaqMan primers and probes for the detection of the indicated target gene in order to compare gene expression between samples. Less fluctuation in amplification indicated less variable gene expression. The three HK genes used as internal reference genes (GUS, BA and B2M) were selected based on these results. IPC, internal positive control; $18 \mathrm{~S}, 18 \mathrm{~S}$ rRNA; huPO, acidic ribosomal protein; huBA, $\beta$-actin; CYC, cyclophilin; GAPDH, glyceraldehyde-3-phosphate dehydrogenase; PGK, phosphoglycerokinase; B2M, $\beta$-2 microglobulin; GUS, $\beta$-glucronidase; HPRT, hypoxanthine ribosyl transferase; TBP, transcription factor IID, TATA binding protein; TfR, transferrin receptor.

at the Toho University Sakura Medical Center (Sakura, Japan) as previously described (15). Written informed consent was obtained from the subjects according to the terms of the Declaration of Helsinki. Non-cancerous tissue, located proximal to the tumor and macroscopically free of disease, was obtained immediately after surgery. The characteristics of the 50 subjects were previously described (15) and there was no bias in the sample population.

The 50 cancerous specimens were grouped according to the histopathological stage (pStage I, II, III and IV), based on the tumor-node-metastasis (TMN) classification of the International Union against Cancer (UICC). Differences in TLR2 and TLR4 expression in each of the pStages and non-cancerous tissues were examined.

To select the optimal internal control gene, the TaqMan ${ }^{\circledR}$ Human Endogenous Control Plate (Applied Biosystems, Inc., Foster City, CA, USA) was used, which contained TaqMan primers and probes for 11 commonly used HK genes and one internal positive control sequence. Non-cancerous and cancerous tissue specimens obtained from CRC patients were used as the test specimens ( 8 samples from 4 patients) to determine the most suitable internal reference genes. One of the non-cancerous tissue specimens was used to calibrate the plate.

This study was approved by the Ethics Committee of the Toho University Sakura Medical Center.

Real-time PCR. RNA was extracted using an RNeasy ${ }^{\circledR}$ Plus Mini kit (Qiagen, Hilden, Germany) and cDNA was synthesized using an AffinityScript ${ }^{\circledR}$ QPCR cDNA synthesis kit (Stratagene, La Jolla, CA, USA), according to the manufacturer's instructions, as previously described (15).

Quantitative real-time PCR was performed using a Stratagene Mx3000P ${ }^{\circledR}$ QPCR System with TaqMan ${ }^{\circledR}$ Gene Expression Master mix. The thermal profile consisted of precycle heat activation at $95^{\circ} \mathrm{C}$ for $10 \mathrm{~min}$, followed by $95^{\circ} \mathrm{C}$ for $15 \mathrm{sec}$ and then $60^{\circ} \mathrm{C}$ for $60 \mathrm{sec}$ for a total of 40 cycles. Data were expressed as fold-induction relative to the RNA amplified at the lowest level. Relative quantification of total gene product in each sample was performed using the comparative $\mathrm{CT}(\Delta \Delta \mathrm{CT})$ method.

The primers and probes used in this study can be found using the assay IDs: Hs00610101_ml for TLR2, Hs00152939_ml for TLR4, and Hs99999903_ml for BA (http://products. appliedbiosystems.com/ab/en/US/adirect/ab).

Statistical analysis. Data were expressed as the means \pm standard deviation (SD). Mean values were compared in groups using the unpaired Student's t-test with two-tailed P-values using StatMate III (ATMS Co., Ltd., Tokyo, Japan). P $<0.05$ was considered to indicate statistically significant difference.

\section{Results}

Detection of the indicated target genes to compare gene expression between sample. The effect of several potential internal control genes on relative expression levels was assessed using the TaqMan ${ }^{\circledR}$ Human Endogenous Control Plate, according to the manufacturer's instructions. The three HK genes selected as internal control genes, GUS, BA and B2M, exhibited minimal variability at expression levels, based on the total threshold cycle, in samples under the experimental conditions used (Fig. 1). Relative quantification of gene expression was performed using each gene individually and together.

TLR2 and TLR 4 expression in cancerous and non-cancerous tissues. TLR4 expression in non-cancerous and cancerous tissues was confirmed in all the 50 subjects using real-time PCR. TLR4 mRNA expression was significantly higher in cancerous compared to non-cancerous tissues when B2M 
Table I. TLR2 and TLR4 expression in cancerous and non-cancerous tissues (mean \pm SD).

\begin{tabular}{|c|c|c|c|c|c|c|}
\hline \multirow[b]{2}{*}{ Receptor } & \multicolumn{2}{|c|}{ BA } & \multicolumn{2}{|c|}{ GUS } & \multicolumn{2}{|c|}{$\mathrm{B} 2 \mathrm{M}$} \\
\hline & NCT & $\mathrm{CT}$ & NCT & $\mathrm{CT}$ & NCT & $\mathrm{CT}$ \\
\hline TLR2 & $2.61 \pm 1.82$ & $6.60 \pm 4.15^{\mathrm{b}}$ & $5.08 \pm 4.44$ & $13.61 \pm 12.26^{\mathrm{a}}$ & $5.14 \pm 3.01$ & $30.84 \pm 22.61^{\mathrm{b}}$ \\
\hline TLR4 & $1.61 \pm 1.04$ & $2.17 \pm 2.22$ & $3.24 \pm 3.40$ & $2.72 \pm 2.37$ & $2.92 \pm 21.13$ & $5.22 \pm 3.23^{b}$ \\
\hline
\end{tabular}

${ }^{\mathrm{a}} \mathrm{P}<0.01 ;{ }^{\mathrm{b}} \mathrm{P}<0.001$. BA, $\beta$-actin; GUS, $\beta$-glucuronidase; $\mathrm{B} 2 \mathrm{M}, \beta$-2 microglobulin; NCT, non-cancerous; $\mathrm{CT}$, cancerous.

Table II. TLR2 and TLR4 expression at various histological stages (mean \pm SD).

\begin{tabular}{|c|c|c|c|c|c|c|}
\hline \multirow[b]{2}{*}{ Receptor (pStage) } & \multicolumn{2}{|c|}{ BA } & \multicolumn{2}{|c|}{ GUS } & \multicolumn{2}{|c|}{$\mathrm{B} 2 \mathrm{M}$} \\
\hline & NCT & CT & NCT & $\mathrm{CT}$ & NCT & $\mathrm{CT}$ \\
\hline TLR2 (I) & $1.76 \pm 0.96$ & $7.02 \pm 4.55^{\mathrm{b}}$ & $2.70 \pm 1.20$ & $8.84 \pm 6.13^{\mathrm{a}}$ & $4.02 \pm 0.15$ & $11.21 \pm 5.64^{\mathrm{a}}$ \\
\hline TLR4 (I) & $1.14 \pm 0.43$ & $2.10 \pm 1.41$ & $1.15 \pm 0.11$ & $1.31 \pm 0.13$ & $1.30 \pm 0.64$ & $5.43 \pm 3.17^{\mathrm{a}}$ \\
\hline TLR2 (II) & $2.89 \pm 2.05$ & $10.90 \pm 8.61^{\mathrm{b}}$ & $5.10 \pm 4.35$ & $18.02 \pm 14.85^{\mathrm{a}}$ & $5.32 \pm 3.40$ & $52.84 \pm 58.88^{b}$ \\
\hline TLR4 (II) & $1.11 \pm 0.55$ & $1.82 \pm 1.74$ & $2.47 \pm 2.63$ & $2.03 \pm 1.37$ & $4.16 \pm 4.37$ & $4.69 \pm 3.37$ \\
\hline TLR2 (III) & $4.02 \pm 3.19$ & $7.73 \pm 5.55^{\mathrm{b}}$ & $5.07 \pm 5.40$ & $12.44 \pm 9.71^{\mathrm{a}}$ & $6.11 \pm 2.83$ & $34.17 \pm 19.96^{c}$ \\
\hline TLR4 (III) & $1.72 \pm 0.78$ & $1.33 \pm 1.09$ & $4.09 \pm 3.08$ & $2.86 \pm 2.50$ & $3.79 \pm 2.00$ & $6.80 \pm 4.00^{\mathrm{a}}$ \\
\hline TLR2 (IV) & $1.77 \pm 1.06$ & $5.59 \pm 1.94^{\mathrm{b}}$ & $1.50 \pm 0.72$ & $5.94 \pm 2.18^{b}$ & $3.94 \pm 1.83$ & $16.64 \pm 10.22$ \\
\hline TLR4 (IV) & $1.67 \pm 1.04$ & $3.50 \pm 3.33$ & $2.65 \pm 1.63$ & $3.92 \pm 3.17$ & $2.86 \pm 1.81$ & $4.63 \pm 0.03$ \\
\hline
\end{tabular}

${ }^{\mathrm{a}} \mathrm{P}<0.05 ;{ }^{\mathrm{b}} \mathrm{P}<0.01 ;{ }^{\mathrm{C}} \mathrm{P}<0.001$. BA, $\beta$-actin; GUS, $\beta$-glucuronidase; $\mathrm{B} 2 \mathrm{M}, \beta-2$ microglobulin; NCT, non-cancerous; $\mathrm{CT}$, cancerous.

was used as the internal control gene $(\mathrm{P}<0.001)$. No significant difference was observed in TLR4 expression between non-cancerous and cancerous tissues when GUS and BA were used as the control genes (Table I). TLR2 mRNA expression was also confirmed in the 50 cancerous and in 49 of the non-cancerous tissue specimens using real-time PCR. TLR2 expression was significantly higher in cancerous compared to non-cancerous tissues when analyzed using each of the three internal control genes $(\mathrm{P}<0.001)$ (Table I).

TLR2 and TLR4 expression according to histological stage. TLR 2 and TLR4 expression was compared between cancerous and non-cancerous tissues at various pStages. TLR4 expression was significantly higher in pStage I and II cancerous compared to non-cancerous tissues when B2M was used as an internal control gene, while no statistically significant differences were detected in pStage II and IV cancerous tissues (Table II). TLR2 expression was significantly higher in pStage I, II and III cancerous compared to non-cancerous tissues with the three control genes ( $p$ Stage I, $\mathrm{P}<0.05$ for the control genes; pStage II, $\mathrm{P}<0.05$ with GUS and $\mathrm{P}<0.01$ with $\mathrm{B} 2 \mathrm{M}$ and $\mathrm{BA}$; pStage III, $\mathrm{P}<0.05$ with GUS and $\mathrm{BA}$ and $\mathrm{P}<0.001$ with $\mathrm{B} 2 \mathrm{M}$ ). In pStage IV tissues, significant differences in TLR2 expression were observed only with GUS and BA $(\mathrm{P}<0.01)$ (Table II). TLR2 expression did not differ significantly in non-cancerous and cancerous tissues in pStage IV with B2M as the control gene.

\section{Discussion}

Common HK genes, such as GAPDH and BA are traditionally used as internal controls for the assessment of gene expression using techniques such as quantitative real-time PCR (12). However, previous studies have indicated that the expression levels of HK genes may be different in various tissues or between normal and diseased tissues $(2,4)$. Shrout et al $(21)$ and Bianchini et al (13) reported that low levels of B2M in CRC tissue might serve as a prognostic indicator in CRC patients with lymph node metastasis. Vandesompele et al (1) have recommended the use of at least three appropriate control genes for the calculation of a normalization factor in view of the inherent variation in the expression of $\mathrm{HK}$ genes.

Bustin (22) proposed the use of the TaqMan ${ }^{\circledR}$ Human Endogenous Control Plate for normalizing mRNA levels in tissue culture cells using HK genes. Other groups have similarly emphasized the convenience of this system for initial screening to select an appropriate internal reference gene $(11,23)$. In the present study, three HK genes (GUS, B2M and BA) were selected as the internal control genes. These genes exhibited a relatively stable expression under the present conditions.

In the majority of cases, consistent results were obtained when GUS and BA were used as the internal control genes. However, TLR4 expression was higher in cancerous compared to non-cancerous tissues, when B2M was used as the internal 
control gene. These results may be associated with the low level of B2M expression in cancerous tissues and are consistent with the findings of Shrout et al (21) and Bianchini et al (13).

\section{Acknowledgements}

This study was supported in part by a grant from the Cancer Research Funds for Patients and Family of the Medical treatment and Welfare Network Chiba, Japan.

\section{References}

1. Vandesompele J, De Preter K, Pattyn F, Poppe B, Van Roy N, DePaepe A and Speleman F: Accurate normalization of real-time quantitative RT-PCR data by genometric averaging of multiple internal control genes. Genome Biol 3: RESEARCH0034, 2002.

2. Bas A, Forsberg G, Hammarström $S$ and Hammarström ML: Utility of the housekeeping genes $18 \mathrm{~S}$ rRNA, $\beta$-actin and glyceraldehyde-3-phosphate-dehydrogenase for normalization in real-time quantitative reverse transcriptase-polymerase chain reaction analysis of gene expression in human $\mathrm{T}$ lymphocytes. Scand J Immunol 59: 566-573, 2004.

3. Radonić A, Thulke S, Mackay IM, Landt O, Siegert W and Nitsche A: Guideline to reference gene selection for quantitative real-time PCR. Biochem Biophys Res Commun 313: 856-862, 2004.

4. Barber RD, Harmer DW, Coleman RA and Clark BJ: GAPDH as a housekeeping gene: analysis of GAPDH mRNA expression in a panel of 72 human tissues. Physiol Genomics 21: 389-395, 2005.

5. van der Woude CJ, Moshage H, Homan M, Klebeuker JH, Jansen PLM and van Dekken H: Expression of apotosis related proteins during malignant progression in chronic ulcerative colitis. J Clin Pathol 58: 811-814, 2005.

6. Ernst PB, Takaishi H and Crowe SE: Helicobacter pylori infection as a model for gastrointestinal immunity and chronic inflammatory disease. Dig Dis 19: 104-111, 2001.

7. Itzkowitz SH and Yio X: Inflammation and cancer IV. Colorectal cancer in inflammatory bowel disease: the role of inflammation. Am J Physiol Gastrointest Liver Physiol 287: G7-G17, 2004.

8. Rutter M, Saunders B, Wilkinson K, Rumbles S, Schofield G, Kamm M, Williams C, Price A, Talbot I and Forbes A: Severity of inflammation is a risk factor for colorectal neoplasma in ulcerative colitis. Gastroenterology 126: 451-459, 2004.

9. Cario E and Podolsky DK: Differential alternation in intestinal epithelial cell expression of Toll-like receptor 3 (TLR3) and TLR4 in inflammatory bowel disease. Infect Immun 68 7010-7017, 2000
10. Schmid H, Cohen CD, Henger A, Irrgang S, Schlondorff D and Kretzler M: Validation of endogenous controls for expression analysis in microdissected human renal biopsies. Kidney Int 64: 356-360, 2003.

11. de Kok JB, Roelofs RW, Giesendorf BA, Pennings JL, Waas ET, Feuth T and Swinkels DW: Normalization of gene expression measurements in tumor tissues: comparison of 13 endogenous control genes. Lab Invest 85: 154-159, 2005.

12. Ohl F, Jung $M, X u$ C, Stephan C, Rabien A, Burkhardt M, Nitsche A, Kristiansen G, Loening SA, Radonić A and Jung K: Gene expression studies in prostate cancer tissue: which reference gene should be selected for normalization? J Mol Med (Berl) 83: 1014-1024, 2005.

13. Bianchini M, Levy E, Zucchini C, Pinski V, Macagno C, De Sanctis P, Valvassori L, Carinci P and Mordoh J: Comparative study of gene expression by cDNA microarray in human colorectal cancer tissues and normal mucosa. Int J Oncol 29: 83-94, 2006.

14. Takeuchi O, Hoshino K, Kawai T, Sanjo H, Takada H, Ogawa T, Takeda K and Akira S: Differential roles of TLR2 and TLR4 in recognition of Gram-negative and Gram-positive bacterial cell wall components. Immunity 11: 443-451, 1999.

15. Nihon-Yanagi Y, Terai K, Murano T, Matsumoto T and Okazumi S: Tissue expression of Toll-like receptors 2 and 4 in sporadic human colorectal cancer. Cancer Immunol Immunother 61: 71-77, 2012

16. Ortega-Cava CF, Ishihara S, Rumi MAK, Kawashima K, Ishimura N, Kazumori H, Udagawa J, Kadowaki Y and Kinoshita Y: Strategic compartmentalization of Toll-like receptor 4 in the mouse gut. J Immunol 170: 3977-3985, 2003.

17. Aderem A and Ulevitch RJ: Toll-like receptors in the induction of the innate immune response. Nature 406: 782-787, 2000.

18. Janeway CA Jr and Medzhitov R: Innate immune recognition. Annu Rev Immunol 20: 197-216, 2002.

19. Akira S and Hemmi H: Recognition of pathogen-associated molecular patterns by TLR family. Immunol Lett 85: 85-95, 2003.

20. Miyake K: Innate immune sensing of pathogens and danger signals by cell surface Toll-like receptors. Semin Immunol 19: 3-10, 2007.

21. Shrout J, Yousefzadeh M, Dodd A, Kirven K, Blum C, Graham A, Benjamin K, Hoda R, Krishana Romano M, Wallace M, Garrett-Mayer E and Mitas M: $\beta-2$ microglobulin mRNA expression levels are prognostic for lymph node metastasis in colorectal cancer patients. Br J Cancer 98: 1999-2005, 2008.

22. Bustin SA: Quantification of mRNA using real-time reverse transcription PCR (RT-PCR): trends and problems. J Mol Endocrinol 29: 23-39, 2002.

23. Dheda K, Huggett JF, Bustin SA, Johnson MA, Rook G and Zumla A: Validation of housekeeping genes for normalizing RNA expression in real-time PCR. Biotechniques 37: 112-119, 2004. 